\title{
ANTHROPOLOGICAL APPROACH TOWARDS MAPPING ADOPTION BARRIERS IN ICT IMPLEMENTATION IN EDUCATION: A CASE OF RURAL INDIA
}

\author{
Avanee Khatri ${ }^{1}$ \\ ${ }^{1}$ Research Scholar, Panjab University, Chandigarh, India, khatriavni@gmail.com
}

\begin{abstract}
One of the areas in which these technological advances are dramatically influencing people's lives is information technology and telecommunications hence the claim that we are in the midst of a 'digital revolution' that is driving us towards an 'information society'. The development of human learning abilities has been changed over the past 60 years of technological innovation starting from the widespread use of the radio, through television, and finally to the mass implementation of computers and information and communication technologies (ICT). With information revolution on the go, shift towards knowledge-based economy is the prime target of all nations of the world. Also, there is a growing concern about the current trends in ICT adoption and use. Throughout the world communities are grappling with the concept of knowledge based development. Education is considered, as the most important contributing factor to nations development and achievement of knowledge economy in the era of information revolution. Education especially the primary and secondary education is important; as it is here the foundations of knowledge are led. The literature on educational technology lacks empirical research on the social practice of information and communication technology (ICT) that would enable us to extend our understanding of the barriers to adoption and integration of ICT in the educational context. The present field study was undertaken with teachers, students, parents and staff of a government primary educational institute in a disadvantaged rural area of India. Research was initiated with the investigation by adapting participatory appraisal methods suitable to a rural context. The anthropological approach used in the present research focuses on the influences of culture and society on the individual adoption behavior; it emphasizes participant observation and academic analysis of behavior through both management and consumer perspectives. The cultural capital in question includes knowledge about ICT product features and qualities, ICT skills, digital literacy, the level of education of family elders, and proficiency in English. Economic capital includes access to electricity, lack of knowledge of the ICT market, a transportation system, and ownership of ICT equipment. Social capital includes distrust of rural and semi-urban sources of ICT purchases, lack of motivation, and access to ICT. In addition to finding ways to facilitate the work of teachers and educational institutions in both formal and non-formal learning environments, the informal learning environment has to be considered. The paper explores that every culture, organizational or national, is different, and not all technologies are equally acceptable in all cultures. It brings forward the ground realities including policy concerns, failures in governmental efforts and community's role in facilitating ICT adoption. It also highlights the role of teacher's in promoting ICT adoption and use in education. The better we understand culture, the better we can maximize the usefulness of new information technology in the workplace.
\end{abstract}

Keywords: ICT4d, educational technology, digital literacy, developing countries, barriers to technology, diffusion of innovations. 


\section{INTRODUCTION}

Information and communication technologies (ICTs) are increasingly recognized to promote the achievement of developmental goals, especially in the education domain. With the United Nations Millennium Declaration to "make available the benefits of new technologies, specifically information and communication" (United Nations, 2005), it is time to address issues in the adoption of ICTs in primary education. This study does not address fundamental scholastic issues existing prior to technology introduction. Rather, it investigates the factors that most influence the potential beneficial impact that ICTs may have for those communities hitherto unfamiliar with technology. Educating the young not only facilitates the acquisition of basic skills such as literacy and numeracy, but also enables a nation's long-term social and economic development (Organisation for Economic Co-Operation and Development [OECD], 2005). The future workforce gets equipped with the necessary skills to succeed in 21 st-century global economies (International Society for Technology in Education [ISTE], 2007), while simultaneously contributing to poverty reduction and human development (UNDP, 2009). However, the ability to reap much of the benefits of educational growth has, for the most part, been limited to the developed economies and to affluent pockets of developing regions.

Developing countries have been unable to seize these advantages fully, as a combined consequence of poverty, inadequately qualified teachers, substandard instruction materials and facilities, and gender discrimination (infoDev, 2003). For these reasons, there is a growing need to expand the capacity of the educational system within developing countries that fall short in meeting the MDG's indicators for educational progress, namely, net enrollment, completion rate, and literacy rate (United Nations, 2003). The role of ICTs, particularly in the domain of education, has been recognized to benefit learning (Banerjee, Cole, Duflo, and Linden, 2005). In addition to facilitating technological literacy and familiarity, students who participate in computer-connected learning environments show increased motivation, greater willingness to tackle difficult questions, and deeper understanding of concepts (Riel, 1992; Weir, 1992). As the development of children's technological competence is increasingly associated with their future employment (Kinyanjui, 2002) in the global knowledge-based workforce (Delannoy, 2000), significant attention has been centered on introducing ICTs in rural schools to assist in leapfrogging educational challenges (International Telecommunication Union [ITU], 2009).

As computer technology becomes increasingly diffused throughout society, especially for populations in resource-constrained settings for whom these tools have long been financially and practically unfeasible, concerns have been raised about the differing access to learning using this technology, and the varying conditions that affect how children experience learning. Much debate surrounds the use of ICTs in education (ICTE), with advocates for (Negroponte, 1995; Papert, 1996), and campaigners against (Oppenheimer, 1997; Peat and Franklin, 2003) the pedagogical benefits ICTs can bring. These views are balanced by researchers (Apkan, 2002; Bork, 2003) who contend that, if properly implemented, ICTs have the potential to enhance teaching and learning in rural classrooms. However, along with the recognition that rural schools lack the financial resources to support extensive

ICT deployments (United Nations Educational, Scientific and Cultural Organization [UNESCO], 2004), concerns have been raised about the need for appropriate educational content and software development (Farrell and Wachholz, 2004). On an infrastructural level, the existence of barriers such as the absence of Internet connectivity and the lack of time and resources for technical support and maintenance, compounded by regular disruptions in power supply, significantly affect ICT use in rural locations (Cope and Ward, 2002; Martins, Steil and Todesco, 2004). Structural requisites, such as ensuring that computer rooms are clean, dust-free, and dry, can also be important considerations often overlooked in the rural context (Tinio, 2002). Moreover, limited physical scholastic infrastructure (Global E-Schools and Communities Initiative [GESCI], 2009), inadequately trained teachers from a technological perspective (Carlson, 2002), and difficulties in integrating ICT within existing curricula (Brock, 2001) are fundamental challenges that need to be addressed.

\subsection{Literature Review}

ICTs and their associated instructional programmes arose in a certain historical context, which is worthy of some discussion. The computer arose in a time and place that was decidedly modernistic. As Carmel (1997) wrote, it is unsurprising that ICTs developed in America given its high levels of military spending, entrepreneurial culture, capitalistic economy and individualistic society. In some sense, ICTs and modern society formed a mutually beneficial loop, fuelling the growth of ICT and further promoting modern ideals.

This paved the way ICT was taught. Literature on ICT education began to appear in the 1960s, and was primarily focused on technical details, programming and the mathematical applications of computing (Brauer, 1985; Ercoli, 1985). From a social standpoint, there were papers exhorting ICT education to "meet the needs of industry" (Department of Education and Science [England] 1967), but there was no discussion on 
designing courses to teach how ICTs could lead to competitive advantage, or how they change aspects of society, or other issues related to politics and the economy. In the 1960s, ICT education tended to be called "computer science". As this discipline went through its growing pains, it was always fighting for legitimacy and trying to find its voice. Practitioners commented that it resided somewhere between the "purest mathematics and the dirtiest engineering" (Oettinger, 1968). Such was the place for ICT education. The intention was to teach students the skills to get good jobs and to meet the needs of the economy (Galliers, 1987).

Installing the hardware infrastructure in schools is often the starting point for ICTE initiatives addressing the first level of the digital divide (Attewell, 2001; Hawkins and Oblinger, 2006). Nonetheless, introducing technology alone may not be sufficient to achieve educational objectives. In most Asian programs, emphasis is often placed on acquiring hardware in schools, with limited consideration given to how it would be used by teachers and students, how it would be incorporated into the curriculum, or the community's attitudes toward technology adoption. Scholars have therefore suggested that access to hardware alone rarely leads to change (Adeya, 2002; Bracey, 2005).

It is essential to recognize that factors influencing communities in the Asian rural context differ considerably from those influencing their urban counterparts, who have an upper hand in using technology due to existing technological familiarity, and economic and educational privileges (Chib and Zhao, 2009; Jhurree, 2005). Studies from technologically advanced countries have found that ICTs support problem-based learning and critical thinking, and that children should be exposed to a variety of more complex programs and approaches that encourage higher-level learning (McGhee and Kozma, 1999). In reality, however, rural children who might not have had the chance even to get basic exposure to technological devices might struggle to engage in higher-level learning. In this case, equipping children with basic technology knowledge and skill-sets should be prioritized (Kozma, 2006).

The ICTE literature has focused on technology adoption rather than developing a comprehensive understanding of the factors that influence adoption and, eventually, the impact of ICTs on educational outcome measures. Supporting the current claims within the ICTE literature, the present study emphasizes that specific community aspects need to be addressed, along with underlying cultural, psychological, and community factors that influence technology adoption. First, the ability to have physical access to technology is captured in the ownership aspect. Community training for technology use and catering to contextually relevant needs represent the other two factors.

\section{METHODOLOGY}

Anthropology is the study of humans, past and present. From the Greek Anthropos (human) and logia (study), the word anthropology itself tells us it is the field that seeks to understand humankind, from the beginnings millions of years ago up to the present day. Anthropology considers how people's behaviors changes over time, and how people and seemingly dissimilar cultures are different and the same. The present study explores the barriers towards adoption of ICT implementation in education from the rural perspective. The perspective of anthropology helps in better understanding of culture, social organizations, class, socio-economic status and many others, which helps in tracing the ground realities.

Context: According to census 2011, the rural to urban ratio in India is $72: 28$, which clearly explains the fact that in a country with maximum population in the world, majority of population resides in rural areas. Therefore, from the perspective of development, rural population needs to be considered on top most priority. The development indicators of a nation for example literacy, poverty, education, health, sanitation, socio-economic status and many more have always been at lowest level and a cause of concern for the politicians as well as administrators. In response to the global call for Education for All, India established the Sarva Shiksha Abhiyan ("Education for All" Movement) in an effort to make primary education universally available. In reality, however, India has a limited basic school infrastructure in place, with an education system facing challenges similar to those in other developing countries (Manzar, Phalachandra, and Sinha, 2005). The present study was conducted in Government senior secondary school of Khanyara village in Dharamshala sub division of Kangra district, Himachal Pradesh. Himachal Pradesh is a beautiful northern state in India. The basic premise of selecting Khanyara as the area of study was that, the government school located in Khanyara was a senior secondary school providing secondary education. The school caters to rural population from in and around six villages, because there is no other school in the area. Also, the school was well equipped with all the government provisions and schemes starting from, mid-day meals to students till $8^{\text {th }}$ standard to providing free uniform and books to students belonging to below poverty line families. The school was equipped with ICT labs for computer education also.

Unit and universe of study: For the present study, the most important approach of Anthropology, 
Ethnography was used as the methodology to pursue research, which included immersion in the area and community of study. In this present research fieldwork was conducted for a period of four months in the area of study. Students in age group 13 to 18 were interviewed studying in classes' IX-XII. Both qualitative and quantitative methods were used to collect data. Ethnographic tools including in-depth interviews, focus group discussions and case studies were broadly used to collect data from students, teachers and officials concerned with education policy implementation. Qualitative research was done to understand the information and educational requirements of 13 to 18 year olds. Along with primary research, a range of published literature in the field of education and use of the Internet and mobile technologies in education were reviewed. An effort was made to build rapport with teachers, students and officials. Also, an attempt was made to meet the respondents in their informal settings apart from the formal school environment, to be one with them for better understanding of their perspectives and needs. In-depth interviews were aimed at getting a better understanding of the children's lifestyle, attitudes and their understanding towards ICTs. The questions to teachers probed the challenges and involvement of parents, since teachers had maximum contact with the local community. The teachers were later interviewed to understand how training in technology could be made appropriate for them. They were asked if they were, first and foremost, interested in being trained to use the ICT, and further, about their attitudes and concerns toward using technology in the classrooms.

\section{DATA ANALYSIS}

Data were collected and reviewed concurrently, with transcripts reviewed and topics catalogued based on recurring issues. The thematic patterns were used as a guideline to explain the community factors that influence the impact of ICT education in rural India. A triangulation of methods such as interviews and observations allowed for the cross-validation of the findings and to add to the emerging descriptions. Respondent comments and interpretations of observation notes were reviewed and interpreted accordingly. In mapping barriers in implementing ICT in education in the present research area, the main theme barriers to introduction of ICTs in schools addressed subthemes as availability of infrastructure, computer access and use, training in ICT skills. The other major themes address teachers and student personal barriers towards ICT in education.

\section{FINDINGS}

It was found that implementation of ICTs in education involves combined efforts from the students, teachers, school administration and government for one is dependant on another. As mentioned in the methodology the school under study was situated in Khanyara village. It was the only educational institution in that area that caters to the educational needs of surrounding villages too. The school witnessed students belonging to low socio-economic status with majority of student's parent's occupation of contracted laborers. Because of the low socio-economic status with average monthly income of 3000-5000 INR (50-80 USD), none of the students possessed computer or laptop at home. Their only source of learning about computers was school. On the contrary, it was fascination to see the impact of mobile technology with mobile penetration almost full, every household possessing at least one mobile handset. But again due to their inefficiency to spend money, the smartphone penetration was very limited. Also, majority of mobile handsets were second hand simple devices used with the purpose of calling by parents. Hence, the only potential source of ICT learning for the youth under study was school provision for computer education. The major findings of the study are elaborately explained below concordant to dominant themes and patterns that emerged from the study.

\section{AVAILABILITY OF INFRASTRUCTURE}

This includes availability of technology and ICT infrastructure in schools. Realizing importance of ICTs in every domain, government of India has taken many initiatives for implementing ICTs in every possible national sector. Hence, Ministry of Human Resource Development has taken steps in promoting and implementing ICTs in education at national level. In the present study scenario there were two ongoing ICT schemes in the school under study. First was the smartlab scheme, in which school was provided with a LCD and other equipments for running, e-classes which, includes CDs of related subject's syllabus to be displayed on the screen. The second ongoing scheme was IP scheme, in which school was provided with computer desktops for running computer classes. In the present school, there were a total of six desktops provided in the IP lab, where computer practical lessons were to be held.

\section{COMPUTER ACCESS AND USE}

The development of ICTs use in India is very uneven, owing to widened gap in urban to rural population. There were total of ten teachers in school. Out of which, there was only one computer teacher. On interviewing him, he pointed towards the lack of proper infrastructure as the major barrier in ICT adoption. He 
explained, with only six desktop computers and hardly one computer class per week, it is difficult to impart proper knowledge of computers and its functions in such less time. Also, the option between drawing and computer makes the students opt for easiest way to score pass marks.

Apart from the physical factors explained above governing adoption and use of ICT in education, it was important to understand other dynamics of personal beliefs and mindsets of teachers, parents and students themselves influencing ICT use directly.

\section{TEACHERS' ATTITUDES AND BELIEFS}

Teachers are change agents. For students and especially in this research it was in school that students had their first encounter with computers. Hence, a role of teacher is of utmost importance in imparting ICT knowledge and implementation. So, teachers were interviewed focusing on their personal beliefs about ICT knowledge, use and teaching medium. The responses from teachers are summed up below:

- Teachers' attitudes towards computers are directly related to principals' attitudes (Pierce and Ball, 2009). Teachers were afraid of the principal and they had no choice and independence but to follow principal's instructions in all possible ways.

- Initially half-hearted about teaching with technology; "belief that using technology would not enhance learning" (Pierce and Ball, 2009). Teacher's responses clearly indicated their anxiety of teaching with ICTs. They find it difficult to teach with ICT and were more comfortable in teaching with their traditional methods.

- Teachers' perception about students' attitudes toward the subject (Pierce and Ball, 2009), e.g., teachers are not convinced that technology use will increase students' interest, motivation, and confidence (Mumtaz, 2000; Pierce and Ball, 2009). Majority of teacher's who were interviewed were of view that, only students from low socio-economic status come here to study, they don't have and cannot afford these technologies. Hence, it is difficult to teach these students as they found these students dull. Teachers also mentioned about the increasing drop out rates among the students, which in itself is greatest barrier in education.

- Teachers' belief that learning new technology will encroach too much on personal time, occurrence of unexpected technological problems will cause greater difficulty, higher use of technology will lower allocable time for completing course contents, and access to technology is too expensive for students (Pierce and Ball, 2009).

- Low teacher expectations and a lack of clear goals for ICT use in schools (Al-Bataineh et al. 2008). Also, there was limited knowledge and experience of ICT in teaching contexts (Honan 2008)

- A lack of specific knowledge about technology and how to combine it with the existing pedagogical content knowledge to support student learning (Hutchison and Reinking 2011). Due to their experience in conventional teaching methods, teachers found it difficult themselves to adopt new teaching method for as they have to themselves start learning about it.

- Uncertainty about the possible benefits of using ICT in the classroom (Yildirim 2007). Teachers themselves were not clear of the benefits of ICT in education; they found it cumbersome and useless.

- Lack of specific and definite ideas about how integrating technology into instruction will improve student learning (Al-Bataineh et al. 2008). This can be attributed to the lack of ICT training for teachers.

\section{STUDENTS' ATTITUDES AND BELIEFS}

Apart from the impact of teachers and parents on students, students themselves had there own inherent beliefs about the ICTs, which was pertinent to explore. Hence, students studying in classes IX-XII were interviewed and an attempt was made to document their understanding about ICTs, use and barriers associated with it. The major barriers towards ICT understanding and adoption are discussed below:

- Female students were less confident than males about using technology (Pierce and Ball, 2009). This can be pointed to the special importance given to boys in the family. On interviewing them it was found that their inherent perception towards technology use was related to the belief that, these things are meant for boys, they are never going to use it, as after schooling, they have to get married. Hence, female students suffered more of computer anxiety.

- High student to computer ratio in schools. The strength of children in government school is enormous 
as compared to number of computers. In the present case there were only six computers available in school. The average number of students in classes 9-12 was 50 per class, and as per the school curriculum there is only one computer lecture per class. Hence, in a year students hardly get to use computers once or twice.

- Another barrier that came forward in the study was the student's inefficiency and anxiety for English language. Coming from the poor background, these students do not have good fluency in English, also till $5^{\text {th }}$ standard students follow Hindi as the medium of education. Hence, they find difficulty in understanding.

- Student found the smartlab classes where the subject content is visually taught as useless. The room where smartclass takes place is a compact room as mentioned by majority of students, hence with high student strength it becomes very difficult for students to sit jam-packed and concentrate on the lesson. Also, majority of the students revealed that hardly 2-3 smart classes are being taken in a year. The students also complained about the disturbance in the material shown and the speed, which cannot be rewind.

- Lack of self-motivation. It was found that students themselves didn't want to learn about computers. Although majority of the students specially boys showed interest and desire in having a mobile phone, but that only due to its entertainment value and the hyper active mobile markets nowadays.

- Computer as an optional subject for students was a major hindrance. Only a few countable numbers of students opt computer as a subject in IX standard because with opting drawing as a subject, it became easy for students to pass.

\section{PARENTS' ATTITUDES AND BELIEFS}

Anthropology stresses on the point that a life of an individual is governed and regulated by number of factors and influences through which an individual passes throughout the lifetime. Parents' are the most important persons in a life of an individual providing an environment that moulds the belief patterns of an individual. In the present study too, keeping this in mind an effort was made to interview the parent's of the students already interviewed to gain a deeper understanding of the whole network of factors influencing ICT penetration. The important contributing factors towards barriers in ICT integration from the parents' are given below:

- The average education level of parent's interviewed was III grade. Hence, this accounts for their unfamiliarity with the computers and other ICTs.

- Belonging to low socio-economic status, they had the perception that these technologies are for rich people.

- Parents also find it difficult and useless to pay for computer fee. They believed it is useless to pay computer fee in school, as the student strength is very high as compared to computers available. Some of them even said, it is better to learn computer from private institute than spending money in school.

- Parents were more supportive of boy's education than girls. It was found some of the parents allowed their sons to opt computer as a subject but not the girls. The parents explained the possible explanation for gender disparity as the girl has to get married and marriage demands some dowry and other expenses. So, parents were of view that it is better to save money for the girl's marriage rather than spending on things which can be of no use.

\section{INTERPRETATIONS AND DISCUSSION}

This exploratory study intended to better understand existing values and attitudes toward technology adoption on the part of teachers and children-the principal users of technology in the classrooms. While many of the existing literature examines the technology for pedagogical purposes, typically in the developed urban context, the present study tries to fill a research gap by highlighting the barriers in ICT adoption and answering how technology adoption can be enabled within a community of rural users.

The community factors that influence the adoption of ICTs in the rural education context can be translated into a need for provision of unbiased technology access to children; a need for maximizing application of local language within technology and content; and a need for equipping teachers with technological skills while creating positive attitudes toward technology adoption (Komathi, 2011). 
This present Indian case study may help guide rural educational policy in a broader global context. It is important to note that the successful implementations of these recommendations are dependent on understanding the complex social and cultural systems in various developing country contexts. Realities of ICT adoption requires an understanding beyond issues of school provisions to other dimensions like gender segregations that starts from the structure and influence of family giving importance to boys. This has implications on attitudes and beliefs of girls towards learning about computers. Interventions aiming to ICT training for teachers should be given prime focus and strict rules should be implemented for hiring teachers with computer education made must as qualifying criteria. It is essential to promote positive approaches in teaching technology to children. It has to be instilled in teachers that computer learning could benefit primary school children and that teachers would have to take on the role as expert mentors who guide, not compete with, children's use of the technology.

Computer as a compulsory subject should be introduced in earlier class curriculum with no extra fee associated with it. High teacher-student ratio and high technology resource versus user ratio are still prevalent. Student-centered customized facilitation is expected from teachers, but teacher-focused customized training and support facilitations are not available.

Furthermore, the change facilitation cannot use the "one size fits all" approach; research and development should be situated and more context sensitive (Belland, 2009). Following Gallivan's (2001) directions, this paper suggests that change agents should facilitate innovation adoption of both the individual level attributes and organizational level attributes, which are experienced as barriers. Further research should use appropriate methods for illustrating dependencies among the barriers of situated contexts. The complexities involved in the relationships of the barriers and their complex dependencies will enable further understanding of the perceptions of the stakeholders and thereby facilitate addressing the root causes.

\section{REFERENCE LIST}

Adeya, N. C. 2002. ICTs and poverty: a literature review. Ottawa: International Development Research Centre. Retrieved from web.idrc.ca/ uploads/user-S/10541291550ICTPovertyBiblio.doc

Al-bataineh, A., S. Anderson, C. Toledo and S. Wellinski. 2008. A study of technology integration in the classroom. Int'l Journal of Instuctional Media 35: 381-387.

Ale, Komathi. 2011. Community factors in technology adoption in primary education: perspectives from rural India. Information Technologies and International Development 7(4): 53-68.

Apkan, J. P. 2002. Which comes first: computer simulation of dissection or a traditional laboratory practical method of dissection? Electronic Journal of Science Education 6(4): 1-18.

Attewell, P. 2001. The first and second digital divides. Sociology of Education 74: 252-259.

Banerjee, A, S. Cole, E. Duflo, and L. Linden. 2005. Remedying education: Evidence from two randomized experiments in India. The Quarterly Journal of Economics 122(3): 1235-1264.

Bork, A. 2003. Interactive learning: twenty years later. Contemporary Issues in Technology and Teacher Education 2(4): 605-611.

Bracey, B. 2005. Introduction: Uniting people, technology and powerful ideas for learning. In Harnessing the potential of ICT for education: a multi-stakeholder approach, B. Bracey and T. Cluver eds., New York: The United Nations Information and Communication Technologies Task Force.

Brauer, W. 1985. On the role of theory in teaching programming. In The role of programming in teaching informatics, M. Griffiths and E. D. Tagg eds, pp. 149-153. North Holland: Netherlands.

Brock, E. 2001. Integrating real practices experience in ICT education. Journal of Information Systems Education 12(3): 133-140.

Carlson, S. 2002. The missing link in educational technology: Trained teachers. Retrieved from http://www.TechKnowLogia.org/TKL Articles/PDF/ 435.pdf

Carmel, E. 1997. American hegemony in packaged software trade and the "Culture of Software". The Information Society 13(1): 125-142.

Chib, A., and J. Zhao. 2009. Sustainability of ICT interventions: lessons from rural projects in China and India. In Communicating for social impact: engaging communication theory, research, and pedagogy, L. Harter and M. J. Dutta eds., ICA 2008 Conference Theme Book. Hampton Press.

Cope, C., and P. Ward. 2002. Integrating learning technology into classrooms: The importance of teachers' 
perceptions. Educational Technology \& Society 5(1): 67-74.

Delannoy, F. 2000. Teacher training or lifelong professional development? Worldwide trends and challenges. TecKnowLogia 2(6): 10-13.

Department of Education, and Science, England. 1967. Computer education: report of an interdepartmental working group. UK: Her Majesty's Stationery Office.

Ercoli, P. 1985. Are there cultural reasons for teaching programming? In the role of programming in teaching informatics, M. Griffiths and E. D. Tagg eds, Pp. 37-42. North Holland: Netherlands.

Farrell, G. and C. Wachholz. 2004. Integrating information and communication technologies in education in Asia and the Pacific: Trends and observations. In Meta-survey on the use of technologies in education in Asia and the Pacific, G. Farrell and C. Wachholz eds., Pp. 265-272. Bangkok: UNESCO.

Galliers, R. B. 1987. Educating information systems managers into the 1990s: the wait example. In Information systems education, R.A. Buckingham, R. A. Hirschheim, F. Land, and C. J. Tully eds, Pp. 167-178, UK: Cambridge University Press.

Global E-Schools and Communities Initiative (GESCI). 2009. Deploying ICTs in schools: a framework for identifying and assessing technology options, their benefits, feasibility and total cost of ownership. Retrieved from http://inesm.education .unesco.org/files/TCO-deploying-framework.pdf

Hawkins, B. L., and D.G. Oblinger. 2006. The myth about the digital divide. Educause Review 41(4): 12-13.

Honan, E. 2008. Barriers to teachers using digital texts in literacy classrooms. Literacy 42: 36-43.

Hutchison, A. and D. Reinking. 2011. Teachers' perceptions of integrating information and communication technologies into literacy instruction: a national survey in the United States. Reading Research Quarterly 46: 312-333.

infoDev. 2003. ICT for development: Contributing to the Millennium Development Goals. Washington, DC: The World Bank.

International Society for Technology in Education (ISTE). 2007. Profiles for technology (ICT) literate students. Retrieved from http://www.iste.org/

International Telecommunication Union. 2009. Information society statistical profiles 2009: Asia and the Pacific. Retrieved from http://www .itu.int/ITUD/ict/material/ISSP09-AP_final.pdf

Jhurree, V. 2005. Technology integration in education in developing countries: guidelines to policy makers. International Education Journal 6(4), 467-483.

Kinyanjui, L. 2002. Preparing a workforce for the evolving information economy: A survey on ICT access and use in Kenya secondary schools. Nairobi: SchoolNet Kenya.

Kozma, R. B. 2006. Monitoring and evaluation of ICT for education impact: a review. In Monitoring and evaluation of ICT in education projects. A handbook for developing countries, D. Wagner, R. Day, T. James, R. Kozma, J. Miller, and T. Unwin eds., Pp. 11-20. Washington, DC: The International Bank for Reconstruction and Development/World Bank.

Manzar, O., B. Phalachandra, and S. Sinha. 2005. Technology in India 2005. Retrieved from http:// defindia.net/files/ET\%20Report\%202005.pdf

Martins, C. B. M. J., A.V. Steil, and J.L. Todesco. 2004. Factors influencing the adoption of the Internet as a teaching tool at foreign language schools. Computers \& Education 42: 353-374.

McGhee, R., and R. B. Kozma. 1999. World links for development: Accomplishments and challenges, monitoring and evaluation annual report. Retrieved from http://info.worldbank.org/etools/ docs/library/36013/sri_world_me_report_1999_00.pdf

Mumtaz, S. 2000. Factors affecting teachers' use of information and communications technology: a review of the literature. Journal of Information Techology for Teacher Education 9(3): 319-342.

Negroponte, N. 1995. Being digital. New York: Vintage Books.

Oettinger, A. G. 1968. Computers and education. In University Education in Computing Science, A. Finerman eds. Pp: 27-38. USA: Academic Press.

Oppenheimer, T. 1997. The computer delusion. The Atlantic Online 280(1): 45-62. 
Organisation for Economic Co-Operation and Development (OECD). 2005. Are students ready for a technology-rich world? what PISA studies tell us. Paris: OECD.

Papert, S. 1996. The connected family: bridging the digital generation gap. Atlanta: Longstreet.

Peat, M. and S. Franklin. 2003. Has student learning been improved by the use of online and offline press. Australian Journal of Educational Technology 19(1): 87-99.

Pierce, R., and L. Ball. 2009. Perceptions that may affect teachers' intention to use technology in secondary mathematics classes. Educational Studies in Mathematics 71(3): 299-317.

Riel, M. 1992. Learning circles: A functional analysis of educational telecomputing. Interactive Learning Environments 2: 15-30.

Tinio, V. L. 2002. Survey of information and communication technology utilization in Philippine public high schools: Preliminary findings. Tokyo, Japan: Center of International Cooperation for Computerization.

United Nations Development Programme (UNDP). 2005. Promoting ICT for human development in Asia: realizing the millennium development goals. Gurgaon, India: Elsevier.

United Nations Development Programme (UNDP). 2009. Human development report 2009. Overcoming Overcoming barriers: Human mobility and development. New York: Palgrave Macmillan.

United Nations Educational, Scientific and Cultural Organization (UNESCO). 2004. Education for all: The quality imperative. EFA Global Monitoring Report 2005. Paris: UNESCO.

United Nations. 2003. Indicators for monitoring the Millennium Development Goals. New York: United Nations.

Weir, S. 1992. Electronic communities of learners: Fact or fiction. TERC Working Paper 3-92. Cambridge, MA: TERC Communications.

Yildirim, S. 2007. Current utilization of ICT in Turkish basic education schools: A review of teachers' ICT use and barriers to integration. International Journal of Instructional Media 34: 171-186. 